\title{
Photoacoustic Measurements of Porphyrin Triplet-State Quantum Yields and Singlet-Oxygen Efficiencies
}

\author{
Marta Pineiro, Ana L. Carvalho, Mariette M. Pereira, A. M. d'A. Rocha Gonsalves, \\ Luís G. Arnaut,* and Sebastião J. Formosinho
}

\begin{abstract}
Photoacoustic calorimetry was used to measure the quantum yields of singlet molecular oxygen production by the triplet states of tetraphenylporphyrin (TPP), $\mathrm{Zn}-\mathrm{TPP}$ and $\mathrm{Cu}-\mathrm{TPP}$ in toluene, yielding values of $0.67 \pm 0.14,0.68 \pm 0.19$ and $0.03 \pm 0.01$, respectively. We show that a novel dichlorophenyl derivative of $\mathrm{Zn}$-TPP is capable of singlet-oxygen production with a $0.90 \pm 0.07$ quantum yield. The synthesis and characterisation of a new photostable chlorin with high absorptivity in the red that is capable of singlet-oxygen production with $0.54 \pm 0.06$ quantum yield is described. Our results suggest that chlorinated chlorins may be interesting new sensitisers for photodynamic therapy.
\end{abstract}

Keywords: metalloporphyrins photoacoustic calorimetry $\cdot$ porphyrinoids $\cdot$ singlet oxygen $\cdot$ sensitizers

\section{Introduction}

The ubiquitous tetrapyrrolic macrocycles play highly diverse roles in biological systems. ${ }^{[1-5]}$ The natural roles of these structures stimulated the search for new applications, exploiting in particular the use of new synthetic porphyrins. ${ }^{[6]}$ One of the more recent and promising applications of porphyrin chemistry in medicine is in the detection and cure of tumours, ${ }^{[7,8]}$ referred to as photodynamic therapy (PDT). The first reports of clinical trials of haematoporphyrin derivatives (HPD) in PDT were followed by systematic research for improved sensitisers over the last 20 years. ${ }^{[9]}$

A good photosensitiser must be able to selectively photodamage the tumour tissue, while being irradiated with visible or, preferably, near-infrared light. Two mechanisms are possible. In one mechanism the excited photosensitiser reacts directly with substrate molecules in the tissue by electron- or hydrogen-transfer reactions (Type I process). In the other, it transfers energy to the ground state of molecular oxygen, generating singlet oxygen $\left({ }^{1} \Delta_{\mathrm{g}}\right)$, which is the tissue-damaging species (Type II process). Evidence favours the role of the

[*] L. G. Arnaut, M. Pineiro, A. L. Carvalho,

M. M. Pereira, A. M. d'A. Rocha Gonsalves, S. J. Formosinho

Chemistry Department, University of Coimbra

3049 Coimbra Codex (Portugal)

Fax: (+351)39-27703

E-mail: lgarnaut@cygnus.ci.uc.pt

S. J. Formosinho

Escola Superior de Ciências e Tecnologia

Universidade Católica Portuguesa

3500 Viseu (Portugal)
Type II photooxygenation process in cells. ${ }^{[7,8]}$ Adequate sensitisers have specific biological and photochemical properties. The desired biological features of the sensitiser are:

1) little or no dark toxicity

2) selective accumulation and prolonged retention in tumour tissues

3) controlled photofading to reduce the unwanted skin photosensitivity side effects and increase light penetration during therapy.

The chemical and photochemical requisites are:

1) stability, purity and long shelf-life

2) high absorption coefficient in the phototherapeutic window $(600-1000 \mathrm{~nm})$

3) high quantum yield for singlet molecular $\mathrm{O}_{2}\left({ }^{1} \Delta_{\mathrm{g}}\right)$ sensitisation.

The most important precursor of singlet oxygen is the triplet state of the sensitiser, and a high singlet-oxygen quantum yield requires at least three sensitiser triplet-state properties: a near-unity quantum yield $\left(\Phi_{\mathrm{T}} \approx 1\right)$, an electronic energy at least $20 \mathrm{~kJ} \mathrm{~mol}^{-1}$ above that of singlet oxygen $\left(E_{\Delta}=\right.$ $\left.94 \mathrm{~kJ} \mathrm{~mol}^{-1}\right)$, and a long lifetime $\left(\tau_{\mathrm{T}}>5 \mu \mathrm{s}\right)$.

The quantum yield of the triplet state of porphyrins and related macrocycles is a critical quantity in determining their efficiency in PDT. However, uncertainties persist concerning the triplet quantum yields of basic members of this family of compounds. For example, studies on the triplet quantum yield of 5,10,15,20-tetraphenylporphyrin (TPP) reported values ranging from as low as $\Phi_{\mathrm{T}}=0.67 \pm 0.07^{[10]}$ to as high as $\Phi_{\mathrm{T}}=$ $0.88 \pm 0.03 .{ }^{[11]}$ The triplet quantum yield of zinc $5,10,15,20$ tetraphenylporphyrinate ( $\mathrm{Zn}-\mathrm{TPP})$ is also subject to some scatter; values of $\Phi_{\mathrm{T}}=0.86^{[12]}$ and $\Phi_{\mathrm{T}}=0.97^{[13]}$ can be found in 




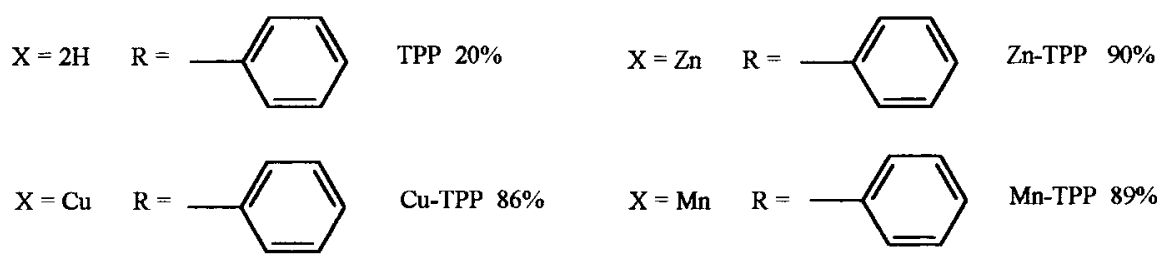<smiles></smiles>
Zn-TDFPP $\quad 87 \%$<smiles>[Y][R]c1c(Cl)cccc1Cl</smiles>

Zn-TDCPP $67 \%$

$X=2 H$<smiles>[R]c1cccc2ccccc12</smiles>

$\mathrm{X}=\mathrm{Zn}$<smiles>[R]c1cccc2ccccc12</smiles>

Zn-TNP $93 \%$<smiles>[R]c1c2nc(c([R])c3ccc([nH]3)c([R])c3nc(c([R])c4ccc1[nH]4)CC3)C=C2</smiles>



TNC

Figure 1. Structural diagram of porphyrin and chlorin macrocycles. Abbreviations: TPP, 5,10,15,20-tetraphenylporphyrin; Zn-TPP, Zn ${ }^{\text {II }}$ 5,10,15,20tetraphenylporphyrinate; $\mathrm{Cu}-\mathrm{TPP}, \mathrm{Cu}^{\mathrm{II}}$ 5,10,15,20-tetraphenylporphyrinate; Mn-TPP, Mn ${ }^{\text {III }}$ 5,10,15,20-tetraphenylporphyrinate; Zn-TDFPP, Zn ${ }^{\text {II }}$ 5,10,15,20-tetrakis(2,6-difluorophenyl)porphyrinate; Zn-TDCPP, Zn ${ }^{\text {II }}$ 5,10,15,20-tetrakis(2,6-dichlorophenyl)porphyrinate; TNP, 5,10,15,20-tetranaphthylporphyrin; Zn-TNP, Zn ${ }^{\text {II }}$ 5,10,15,20-tetranaphthylporphyrinate; TNC, 5,10,15,20-tetranaphthylchlorin.

the literature. The various methods available for measuring the quantum yield of singlet-oxygen production have been recently reviewed, ${ }^{[14]}$ and the value of 0.62 was selected as the standard value for $\Phi_{\Delta}$ of TPP in aerated $\mathrm{CCl}_{4}$. Other $\Phi_{\Delta}$ values relevant to this work are $0.68-0.93$ for $\mathrm{Zn}-\mathrm{TPP}$ in aerated benzene or toluene and $<0.01$ for $\mathrm{Cu}-\mathrm{TPP}$ in aerated $\mathrm{CCl}_{4}$. The use of photothermal methods to measure $\Phi_{\Delta}$, pioneered by Braslavsky and co-workers, ${ }^{[15,16]}$ is particularly relevant to this work.

\footnotetext{
Abstract in Portuguese: $A$ calorimetria fotoacústica foi utilizada para determinar os rendimentos quânticos de formação de oxigénio singuleto molecular pelos estados tripleto de TPP, $\mathrm{Zn}-\mathrm{TPP}$ e $\mathrm{Cu}-\mathrm{TPP}$ em tolueno, onde TPP representa a tetrafenilporfirina na sua forma protonada ou desprotonada, tendo-se obtido $0.67 \pm 0.14,0.68 \pm 0.19$ e $0.031 \pm 0.01$, respectivamente. Um novo derivado da $\mathrm{Zn}-\mathrm{TPP}$, com átomos de cloro nas posições orto do grupo fenilo, produz oxigénio singuleto com um rendimento quântico de 0.90土0.07. É descrita a síntese e feita a caracterização de uma nova clorina foto-estável, capaz de produzir oxigénio singuleto com um rendimento quântico de $0.54 \pm 0.06$. Estes resultados sugerem que clorinas cloradas podem ser sensibilizadores apropriados para a terapia fotodinâmica.
}

This work reports the use of photoacoustic calorimetry (PAC), ${ }^{[17,18]}$ to measure energy-transfer rates and singletoxygen sensitisation quantum yields for a selected range of porphyrins and a chlorin (Figure 1). Some of these species are new and include basic structures that can be derivatized with more polar groups, notably hydroxyl and sulfonamide, ${ }^{[19]}$ which modulate the solubility of the photosensitisers and their selective accumulation in specific tissues. ${ }^{[20]}$

\section{Results}

Porphyrin synthesis: 5,10,15,20-Tetrakisarylporphyrins have a simple basic structure, but their characteristics can be modified by peripheral structural changes. The methodology first described by Rothemund in $1935^{[21]}$ and modified by Adler in $1967^{[22]}$ was recently improved by Rocha Gonsalves et al. ${ }^{[23]}$ This methodology is now useful for the preparation of large amounts of a wide range of pure porphyrins, which were previously very difficult or impossible to prepare. A source of potentially useful new porphyrins for PDT applications became available.

In our approach, the aldehyde and pyrrole are made to react in acetic acid or propionic acid in the presence of nitrobenzene at $120^{\circ} \mathrm{C}$ to give, very often by direct crystal- 
lisation, the corresponding porphyrin free of any chlorin contamination. Yields of porphyrins are presented in Figure 1, and their full characterisation is described in the Experimental Section. The effect of nitrobenzene as oxidant and aromatizing agent was described in the synthesis of other aromatic compounds ${ }^{[2,25]}$ and also in the oxidation of porphyrinogen to porphyrins or chlorins. ${ }^{[26]}$

The $\mathrm{Zn}$ and $\mathrm{Cu}$ complexes were easily prepared by refluxing the porphyrins in the presence of the desired acetate salt with dimethylformamide as solvent. ${ }^{[27]}$ Yields are presented in the Experimental Section. Our interest in obtaining compounds with high absorption coefficients prompted us to synthesise 5,10,15,20-tetranaphthylchlorin (TNC) by refluxing the corresponding porphyrin in $\gamma$-picoline in the presence of $p$ toluenesulfonylhydrazine and sodium carbonate for about 6 hours. ${ }^{[28]}$ After preparative TLC purification, the new 5,10,15,20-tetranaphthylchlorin was isolated; its full characterisation is presented in the Experimental Section.

Porphyrin photophysics and photochemistry: The relevant data from the absorption and luminescence spectra of the porphyrins and chlorin are summarised in Table 1 . The concentrations used in our spectroscopic and PAC studies were in the $10^{-7}-10^{-5} \mathrm{M}$ range. The Beer-Lambert Law was always obeyed in this concentration range, and we found no evidence for aggregation. The present results are in good agreement with the available literature data for TPP and the corresponding porphyrinates. ${ }^{[29-31]}$ The spectroscopic singlet-state energies $\left(E_{\mathrm{S}}\right)$ were obtained from the intersection of the normalised absorption and fluorescence spectra. In Figure 2 we show the absorption, fluorescence excitation and fluorescence emission spectra of TNC. The Stokes shifts of the free bases are very small, and the spectroscopic energies are nearly identical to the relaxed energies of the singlet states. The same is probably true for the triplet states $^{[32]}$, and the



Figure 2. Absorption, fluorescence excitation and emission (normalised) spectra of TNC in toluene at room temperature. The phosphorescence spectrum of TNC was obtained in deaerated toluene at $77 \mathrm{~K}$.

Table 1a. Absorption and luminescence data of the free bases in deaerated toluene solutions.

\begin{tabular}{|c|c|c|c|c|c|c|c|c|c|c|c|c|}
\hline & \multicolumn{5}{|c|}{ Absorption $\lambda_{\max }[\mathrm{nm}]\left(\varepsilon\left[\mathrm{M}^{-1} \mathrm{~cm}^{-1}\right]\right)$} & \multicolumn{2}{|c|}{$\begin{array}{l}\text { Fluorescence } \\
\lambda_{\max }[\mathrm{nm}](\mathrm{RT})\end{array}$} & \multicolumn{2}{|c|}{$\begin{array}{l}\text { Phosphorescence } \\
\lambda_{\max }[\mathrm{nm}](77 \mathrm{~K})\end{array}$} & \multirow[t]{2}{*}{$\begin{array}{l}E_{\mathrm{S}} \\
{\left[\mathrm{kJ} \mathrm{mol}^{-1}\right]}\end{array}$} & \multirow[t]{2}{*}{$\Phi_{\mathrm{F}}$} & \multirow[t]{2}{*}{$\begin{array}{l}E_{\mathrm{T}} \\
{\left[\mathrm{kJ} \mathrm{mol}^{-1}\right]}\end{array}$} \\
\hline & $\mathrm{Q}_{\mathrm{x}}(0-0)$ & $\mathrm{Q}_{\mathrm{x}}(1-0)$ & $\mathrm{Q}_{\mathrm{y}}(0-0)$ & $\mathrm{Q}_{\mathrm{y}}(1-0)$ & $\mathrm{B}(0-0)$ & $\mathrm{Q}(0-0)$ & $\mathrm{Q}(0-1)$ & $\mathrm{T}(0-0)$ & $\mathrm{T}(0-1)$ & & & \\
\hline TPP & $\begin{array}{l}649.8 \\
\left(9.6 \times 10^{3}\right)\end{array}$ & $\begin{array}{l}592.0 \\
\left(1.0 \times 10^{4}\right)\end{array}$ & $\begin{array}{l}548.0 \\
\left(1.16 \times 10^{4}\right)\end{array}$ & $\begin{array}{l}514.6 \\
\left(1.8 \times 10^{4}\right)\end{array}$ & $\begin{array}{l}418.8 \\
\left(2.67 \times 10^{5}\right)\end{array}$ & 652 & 719 & & & $183.9 \pm 0.3$ & $0.10 \pm 0.01$ & $138.0^{[\mathrm{a}]}$ \\
\hline TNP & $\begin{array}{l}654.0 \\
\left(5.16 \times 10^{3}\right)\end{array}$ & $\begin{array}{l}589.5 \\
\left(8.61 \times 10^{3}\right)\end{array}$ & $\begin{array}{l}548.5 \\
\left(7.67 \times 10^{3}\right)\end{array}$ & $\begin{array}{l}514.0 \\
\left(2.4 \times 10^{4}\right)\end{array}$ & $\begin{array}{l}423.0 \\
\left(3.81 \times 10^{5}\right)\end{array}$ & 654 & 715 & 766 & 778 & $183.8 \pm 0.3$ & $0.16 \pm 0.02$ & $153.9 \pm 1.9$ \\
\hline TNC & $\begin{array}{l}652.0 \\
\left(3.7 \times 10^{4}\right)\end{array}$ & $\begin{array}{l}601.8 \\
\left(1.9 \times 10^{3}\right)\end{array}$ & $\begin{array}{l}542.8 \\
\left(4.5 \times 10^{3}\right)\end{array}$ & $\begin{array}{l}517.0 \\
\left(1.0 \times 10^{4}\right)\end{array}$ & $\begin{array}{l}423.4 \\
\left(1.57 \times 10^{5}\right)\end{array}$ & 657 & 721 & 775 & & $182.9 \pm 0.7$ & $0.36 \pm 0.02$ & $154.5 \pm 0.7$ \\
\hline
\end{tabular}

[a] $\operatorname{Ref}[27]$.

Table 1b. Absorption and luminescence data of the free bases in deaerated toluene solutions.

\begin{tabular}{|c|c|c|c|c|c|c|c|c|c|c|c|}
\hline & \multicolumn{3}{|c|}{ Absorption $\lambda_{\max }[\mathrm{nm}]\left(\varepsilon\left[\mathrm{M}^{-1} \mathrm{~cm}^{-1}\right]\right)$} & \multicolumn{3}{|c|}{ Fluorescence $\lambda_{\max }[\mathrm{nm}](\mathrm{RT})$} & \multicolumn{2}{|c|}{$\begin{array}{l}\text { Phosphorescence } \\
\lambda_{\max }[\mathrm{nm}](77 \mathrm{~K})\end{array}$} & \multirow[t]{2}{*}{$E_{\mathrm{S}}\left[\mathrm{kJ} \mathrm{mol}^{-1}\right]$} & \multirow[t]{2}{*}{$\Phi_{\mathrm{F}}$} & \multirow[t]{2}{*}{$E_{\mathrm{T}}\left[\mathrm{kJ} \mathrm{mol}^{-1}\right]$} \\
\hline & $\mathrm{Q}(0-0)$ & $\mathrm{Q}(1-0)$ & $\mathrm{B}(0-0)$ & $\mathrm{Q}(0-0)$ & $\mathrm{Q}(0-1)$ & $\mathrm{Q}(0-2)$ & $\mathrm{T}(0-0)$ & $\mathrm{T}(0-1)$ & & & \\
\hline Zn-TPP & $\begin{array}{l}588.4 \\
\left(2.8 \times 10^{3}\right)\end{array}$ & $\begin{array}{l}549.6 \\
\left(1.21 \times 10^{4}\right)\end{array}$ & $\begin{array}{l}423.4 \\
\left(4.52 \times 10^{5}\right)\end{array}$ & 600 & 648 & 715 & 757 & - & $201.5 \pm 2.0$ & $0.033 \pm 0.005$ & $160.0 \pm 1.0$ \\
\hline $\mathrm{Zn}-\mathrm{TNP}$ & $\begin{array}{l}583 \\
\left(8.28 \times 10^{2}\right)\end{array}$ & $\begin{array}{l}549.2 \\
\left(1.56 \times 10^{4}\right)\end{array}$ & $\begin{array}{l}426.2 \\
\left(2.73 \times 10^{5}\right)\end{array}$ & 595 & 644 & & 770 & - & $203.5 \pm 2.1$ & $0.077 \pm 0.005$ & $157.0 \pm 1.0$ \\
\hline Zn-TDFPP & & $\begin{array}{l}546.0 \\
\left(1.45 \times 10^{4}\right)\end{array}$ & $\begin{array}{l}420.8 \\
\left(3.15 \times 10^{5}\right)\end{array}$ & 588 & 644 & 720 & 737 & - & $211.5 \pm 7.8$ & $<10^{-4}$ & $160.3 \pm 1.0$ \\
\hline Zn-TDCPP & $\begin{array}{l}586.6 \\
\left(3.6 \times 10^{3}\right)\end{array}$ & $\begin{array}{l}550.4 \\
\left(1.22 \times 10^{4}\right)\end{array}$ & $\begin{array}{l}423.8 \\
\left(2.42 \times 10^{5}\right)\end{array}$ & 595 & 652 & 725 & 754 & - & $202.7 \pm 1.4$ & $<10^{-4}$ & $163.9 \pm 1.9$ \\
\hline $\mathrm{Cu}-\mathrm{TPP}$ & & $\begin{array}{l}539.8 \\
\left(1.65 \times 10^{4}\right)\end{array}$ & $\begin{array}{l}418.4 \\
\left(2.4 \times 10^{5}\right)\end{array}$ & & [a] & [a] & 738 & - & $205.3^{[\mathrm{b}]}$ & [a] & $163.7 \pm 1.2$ \\
\hline
\end{tabular}

[a] We observe a residual fluorescence atributable to TPP, suggesting that our sample of Cu-TPP is only 98\% pure. [b] Ref. [29]. 
maximum of the highest energy phosphorescence band was used to obtain the triplet energies $\left(E_{\mathrm{T}}\right)$ presented in Table 1 . The Stokes shifts of the zinc porphyrins correspond to 3$4 \mathrm{~kJ} \mathrm{~mol}^{-1}$. Thus, we add $1.5 \mathrm{~kJ} \mathrm{~mol}^{-1}$ to the energy corresponding to the maximum of the first vibrational band in the phosphorescence spectrum of $\mathrm{Zn}$-porphyrins to obtain the $E_{\mathrm{T}}$ energies presented in Table 1 . The same procedure was followed to obtain the triplet energy of $\mathrm{Cu}$-TPP from the the phosphorescence maximum obtained in this work $\left(\lambda_{\max }=\right.$ $738 \mathrm{~nm}$ ), which is in good agreement with that reported by Harriman. ${ }^{[31]}$

Time-resolved PAC is based on the measurement of the acoustic wave generated by the heat released in the nonradiative processes following electronic excitation. The experimental wave (E-wave) of the sample studied is compared with that of the pressure transducer (T-wave). The T-wave is obtained with a calorimetric reference absorbing the same fraction of light as the sample and releasing it as thermal energy in a time much shorter than the transducer oscillation frequency. The phase and amplitude differences between the T- and E-wave allow for the simultaneous determination of the thermal energy released by the transients and their lifetimes. Typical background-corrected reference and sample signals are shown in Figure 3.

Co-TPP and $\mathrm{Zn}-\mathrm{TPP}$ have been used as PAC references. ${ }^{[32]}$ Whereas the first of these compounds is radiationless, the use of the second one in PAC requires a correction for its fluorescence. The use of 5,10,15,20-tetrakis ( $p$-sulfonylphenyl)porphyrin as calorimetric reference in aqueous solutions ${ }^{[33]}$ has been shown to be inadvisable. ${ }^{[34]}$ The same is probably true for any compounds yielding long-lived tran- sients. For this reason, we selected $\mathrm{Mn}-\mathrm{TPP}$ as the calorimetric reference for our PAC studies in the visible and tested it against reliable calorimetric references in the UV and visible. It is known than Mn-TPP is very weakly luminescent, ${ }^{[35,36]}$ is soluble in a wide range of solvents and absorbs strongly in the 350-550 $\mathrm{nm}$ region. The absorption spectrum of Mn-TPP did not change as a result of prolonged irradiation with the $\mathrm{N}_{2}$ laser. We compared the acoustic waves of $\mathrm{Mn}$-TPP and 2-hydroxybenzophenone (HBP), an established PAC reference for UV irradiation, ${ }^{[17]}$ using the $\mathrm{N}_{2}$ laser. The linearity of the photoacoustic response of Mn-TPP with the fraction of laser energy absorbed is not distinguishable from that of HBP in toluene solutions. We also tested the photoacoustic response of $\mathrm{Mn}-\mathrm{TPP}$ with irradiation at $337 \mathrm{~nm}$ in ethanol/water ( $1: 1$ by volume) against that of $\mathrm{K}_{2} \mathrm{CrO}_{4}$. When the fraction of energy absorbed is less than $50 \%$ of the $\mathrm{N}_{2}$ laser energy, the photoacoustic responses of $\mathrm{Mn}-\mathrm{TPP}$ and $\mathrm{K}_{2} \mathrm{CrO}_{4}$ solutions are linear (correlation coefficient better than 0.990) and have indistinguishable slopes. Mn-TPP and $\mathrm{K}_{2} \mathrm{CrO}_{4}$ give slightly larger waves than HBP in this solvent mixture. It is known that the ground-state repopulation of HPB in non-hydrogen-bonding solvents is $35 \pm 5 \mathrm{ps}$, but in ethanol a fraction of the molecules populate the triplet state, which has a $1.5 \mathrm{~ns}$ lifetime. ${ }^{[37]}$ This advises against the use of HPB as a PAC reference in hydrogen-bonding solvents. Finally, we tested Mn-TPP against trans- $\beta$-carotene (Aldrich) in toluene at $421 \mathrm{~nm}$, because trans- $\beta$-carotene has a singletstate lifetime of $8.4 \pm 0.6 \mathrm{ps}^{[38]}$ and a fluorescence quantum yield of $6 \times 10^{-5}$. $^{[39]}$ The photoacoustic responses of Mn-TPP and trans- $\beta$-carotene are linear with the fraction of laser energy absorbed and have identical slopes.

We interpret the waves of $\mathrm{N}_{2}$-saturated samples with two sequential exponentials, the first one for the formation of the triplet state of the sensitiser and the second one for its decay (Figure 4). The formation of the triplet state is faster than the time resolution of our experiments, and we arbitrarily set the lifetime of the first exponential decay to $\tau_{1}=1 \mathrm{~ns}$; smaller values of $\tau_{1}$ do not change the other parameters in the deconvolution. This is not strictly true for $\mathrm{Cu}-\mathrm{TPP}$, because $\tau_{2}$ is small. For this system we set $\tau_{1}$ to $0.1 \mathrm{~ns}$. We interpreted the waves of airsaturated samples with three sequential exponentials, the second one representing the two decay channels now available for the triplet (energy transfer to oxygen or nonradiative decay to the ground state), and the last one associated with the decay of singlet oxygen. Each decay step is described by two parameters: the lifetime of the transient and the fraction of thermal energy released in that lifetime (Figure 4). The convolution of the reference wave with parameters of the kinetic model for the decay of transient species gives a calculated E-wave. The appropriateness of the kinetic model and its parameters to describe the observed E-wave can be evaluated by the difference between the amplitudes of observed
Figure 3. Typical sample photoacoustic wave, E-wave (obs) and reference wave (T-wave), obtained in a PAC experiment. The E- and T-waves depicted were corrected for the background signal and normalised. The normalisation factor is the reciprocal of the largest absolute value of the T-wave. The sample (TNP), reference (Mn-TPP) and solvent (toluene) data were obtained under the following experimental conditions: irradiation at $517 \mathrm{~nm}$ of $\mathrm{N}_{2}$ saturated solutions with a filter with $93 \%$ transmittance; absorbance of 1.50 at $517 \mathrm{~nm}$; solution flow of $1 \mathrm{~mL} \mathrm{~min}^{-1}$. The calculated wave, E-wave (calcd), was obtained with two sequential exponential decays with lifetimes $\tau_{1}=1 \mathrm{~ns}$ and $\tau_{2}=5.5 \mu \mathrm{s}$ and fractions of heat released $\phi_{1}=0.2995$ and $\phi_{2}=0.3052$. Res $=$ E-wave(calc) - E-wave(obs). 



Figure 4. Photoinduced processes: a) in the absence and b) in the presence of molecular oxygen. Full lines: radiative processes; dashed lines: radiationless processes. $\Delta E_{\mathrm{r}}$ represents the relaxation energy of the ground-state species formed radiatively from the lowest excited singlet state. In our PAC measurements the radiationless processes in a) are described by two sequential exponentials: formation of the triplet state and internal conversion to the ground state, followed by decay of the triplet. In b) there are three sequential exponentials: formation of the triplet state and internal conversion to the ground state, followed by decay of the triplet by intersystem crossing or energy transfer to oxygen and, finally, the decay of singlet oxygen.

authors reported that the fluorescence yield of $\mathrm{Zn}^{\mathrm{II}} 5,10,15,20$-tetrakis(2-chlorophenyl)porphyrinate was larger than that of $\mathrm{Zn}-\mathrm{TPP}$. This unexplained result has no parallel in $\mathrm{Zn}$-TDCPP. Actually we find that introducing two halogens in the ortho positions of the phenyl ring is as effective in quenching fluorescence as halogenation in the meso positions of the porphyrin. ${ }^{[41]}$

Energy conservation in $\mathrm{N}_{2}$-saturated samples requires that the energy of the laser light absorbed $\left(E_{\mathrm{h} v}\right)$ be given by Equation (1), where $E_{\mathrm{F}}$ is the integrated radiative

$E_{\mathrm{h} v}\left(\mathrm{~N}_{2}\right)=E_{\mathrm{F}}+E_{\mathrm{h} v} \phi_{1}+E_{\mathrm{h} v} \phi_{2}$

energy of the singlet state, $\phi_{1}$ and $\phi_{2}$ are the fractions of laser energy released as thermal energy in the lifetimes $\tau_{1}$ and $\tau_{2}$, respectively. The spectroscopic energy of the singlet $\left(E_{\mathrm{S}}\right)$ is an upper limit of $E_{\mathrm{F}}$. This is given by Equation (2),

and calculated E-waves at each decay time. As shown in Figure 3, that difference is typically $1 / 100$ of the amplitude of the sample wave. The decay parameters were obtained by deconvolution of the background-corrected and normalised E- and T-waves with the algorithm described by Melton and co-workers. ${ }^{[40]}$

The fractions of laser energy released by each system were measured at four different laser intensities. In some systems, the first fraction of energy released varied with the laser intensity. We used the Student's $t$ test, at the $95 \%$ confidence level, to decide whether the values obtained at the different laser energies were significantly different. When the differences were significant, we plotted the first fraction of energy released as a function of the laser energy and obtained linear correlation coefficients greater than 0.96 . The difference was assigned to transient - transient absorption and was corrected by extrapolating the fraction of energy released to zero laser intensity.

\section{Discussion}

The absorption and emission spectra of porphyrins and chlorin exhibit the typical features of this class of compounds. It is worth mentioning the large molar absorption coefficient of the $\mathrm{Q}_{\mathrm{x}}(0,0)$ band of TNC $\left(\varepsilon_{652}=37000 \mathrm{M}^{-1} \mathrm{~cm}^{-1}\right)$.

The series of halogenated $\mathrm{Zn}^{\mathrm{II}}$ complexes show fluorescence quenching due to the heavy-atom effect in the intersystem-crossing rate. This effect was also described by Quimby and Longo ${ }^{[30]}$ for halogen substituents positioned on phenyl rings of the free base and $\mathrm{Zn}^{\mathrm{II}} 5,10,15,20$-tetrakis(2-chlorophenyl)porphyrinates in benzene. However, these where $I_{\mathrm{F}}$ and $I_{0}$ are the intensities of emitted and absorbed light, and accounts for the energy emitted by the singlet at each frequency. For a Gaussian emission band, Equation (2) can be approximated by Equation (3), where $E_{\tilde{v}_{\max }}$ is the energy at the maximum fluorescence intensity.

$E_{\mathrm{F}}=\int E_{\mathrm{F}}(v) I_{\mathrm{F}}(v) / I_{0} \mathrm{~d} v$

$E_{\mathrm{F}}=E_{v_{\max }} \Phi_{\mathrm{F}}$

When two or more emission bands are observed, they can be broken into a series of Gaussians, each centred around a maximum. The thermal energy released in a time shorter than the resolution of the $2.25 \mathrm{MHz}$ transducer $\left(\tau_{1}<10 \mathrm{~ns}\right)$ is due to the formation of the relaxed singlet followed by the formation of the triplet and by the internal conversion to the ground state (internal conversion quantum yield $\Phi_{\text {IC }}$ ). The ground-state species formed by fluorescence also relax in this time window and contribute $\left(\Delta E_{\mathrm{r}} \Phi_{\mathrm{F}}\right)$ to the thermal energy dissipated in lifetime $\tau_{1}$ [Eq. (4)].

$E_{\mathrm{h} v} \phi_{1}=\left(E_{\mathrm{h} v}-E_{\mathrm{S}}\right)+\left(E_{\mathrm{S}}-E_{\mathrm{T}}\right) \Phi_{\mathrm{T}}+E_{\mathrm{S}} \Phi_{\mathrm{IC}}+\Delta E_{\mathrm{r}} \Phi_{\mathrm{F}}$

The thermal energy released in the longer decay is associated with the triplet-state energy [Eq. (5)], but triplets with lifetimes longer than $\tau_{2}>10 \mu$ s are difficult to follow with

$E_{\mathrm{h} v} \phi_{2}=E_{\mathrm{T}} \Phi_{\mathrm{T}}$

the $2.25 \mathrm{MHz}$ transducer. In such cases, $\Phi_{\mathrm{T}}$ can be obtained from Equation (4) from the value of $\phi_{1}$ determined by PAC, $E_{\mathrm{T}}$ from phosphorescence measurements (Table 1) and Equa- 
tion (6), where $\Phi_{\mathrm{F}}$ is given by fluorescence measurements (Table 1). From Equations (4) and (6) we obtain Equation (7), because $E_{\mathrm{S}}=E_{v_{\max }}+\Delta E_{\mathrm{r}}$. The values of $\Phi_{\mathrm{T}}$ determined by this procedure are presented in Table 2 .

$\Phi_{\mathrm{IC}}=1-\Phi_{\mathrm{T}}-\Phi_{\mathrm{F}}$

$\Phi_{\mathrm{T}}=\left[\left(1-\phi_{1}\right) E_{\mathrm{h} v}-\Phi_{\mathrm{F}} E_{\nu_{\max }}\right] E_{\mathrm{T}}$

Energy conservation in air-saturated samples yields Equation (8), where $E_{\mathrm{h} v} \phi_{1}, E_{\mathrm{h} v} \phi_{2}$ and $E_{\mathrm{h} v} \phi_{3}$ are given by Equations (9), (10) and (11), respectively, and $\Phi_{\text {isc }}$ represents the intersystem-crossing quantum yield from the triplet to the ground state in the presence of oxygen $\left(\Phi_{\mathrm{T}} f_{\Delta}^{\mathrm{T}}+\Phi_{\mathrm{isc}}=\Phi_{\mathrm{T}}\right)$.

$E_{\mathrm{h} v}(\mathrm{air})=E_{v_{\max }} \Phi_{\mathrm{F}}+E_{\mathrm{h} v} \phi_{1}+E_{\mathrm{h} v} \phi_{2}+E_{\mathrm{h} v} \phi_{3}$

$E_{\mathrm{h} v} \phi_{1}=\left(E_{\mathrm{h} v}-E_{\mathrm{S}}\right)+\left(E_{\mathrm{S}}-E_{\mathrm{T}}\right) \Phi_{\mathrm{T}}+E_{\mathrm{S}} \Phi_{\mathrm{IC}}+\Delta E_{\mathrm{r}} \Phi_{\mathrm{r}}$

$E_{\mathrm{h} \nu} \phi_{2}=\left(E_{\mathrm{T}}-E_{\Delta}\right) \Phi_{\mathrm{T}} f_{\Delta}^{\mathrm{T}}+E_{\mathrm{T}} \Phi_{\mathrm{isc}}$

$E_{\mathrm{h} \nu} \phi_{3}=E_{\Delta} \Phi_{\mathrm{T}} f_{\Delta}^{\mathrm{T}}$

The decay of singlet oxygen in toluene $\left(\tau_{\Delta}=17.4 \mu \mathrm{s}^{[42]}\right)$ is difficult to follow with the $2.25 \mathrm{MHz}$ transducer. However, we can obtain the fraction of triplet states quenched by oxygen, which gives singlet oxygen $\left(f_{\Delta}^{\mathrm{T}}\right)$ either by rearranging Equation (10) to Equation (12) or by adding Equations (9) and (10) together to give Equation (13). The values of $f_{\Delta}^{\mathrm{T}}$ and $\Phi_{\Delta}$ $\left(=\Phi_{\mathrm{T}} f_{\Delta}^{\mathrm{T}}\right)$ presented in Table 2 were obtained with Equation (12) because they are not sensitive to cumulative errors in the measurement of $\phi_{1}$ and $\phi_{2}$.

$\Phi_{\mathrm{T}} f_{\Delta}^{\mathrm{T}}=\frac{\left(\Phi_{\mathrm{T}} E_{\mathrm{T}}-E_{\mathrm{h} \nu} \phi_{2}\right)}{E_{\Delta}}$

$\Phi_{\mathrm{T}} f_{\Delta}^{\mathrm{T}}=\frac{\left(1-\phi_{1}-\phi_{2}\right) E_{\mathrm{h} v}+\left(1-\Phi_{\mathrm{T}}\right) E_{\mathrm{T}}-E_{\mathrm{S}} \Phi_{\mathrm{F}}}{E_{\Delta}}$

It has been argued that structural volume changes accompany thermal expansion in the triplet state formation of some porphyrins, and that both contribute to PAC signals. ${ }^{[34,43]}$ The relevance of such structural volume changes to our studies can be assessed by use of $\mathrm{Zn}$-TDCPP, because its triplet decays in the time window of our experiments, and because the energy lost by room-temperature luminescence can be neglected. Equation (7) with the experimental value of $\phi_{1}=0.4121 \pm$ $0.058, \Phi_{\mathrm{T}} \approx 1$ and $\Phi_{\mathrm{F}} \approx 0$, gives $E_{\mathrm{T}}=167.2 \pm 0.5 \mathrm{~kJ} \mathrm{~mol}^{-1}$ in good agreement with the energy obtained from phosphorescence $\left(E_{\mathrm{T}}=163.9 \pm 1.9 \mathrm{~kJ} \mathrm{~mol}^{-1}\right)$. On the other hand, Equation (5) with the experimental value of $\phi_{2}=0.487 \pm 0.197$, gives $E_{\mathrm{T}}=139 \pm 56 \mathrm{~kJ} \mathrm{~mol}^{-1}$. In this system we obtain $\phi_{1}+$ $\phi_{2}=0.90 \pm 0.25$ in the absence of oxygen. The large uncertainty in the value of $\phi_{2}$ reflects the difficulty of measuring microsecond lifetimes with the $2.25 \mathrm{MHz}$ transducer.

According to the mechanism of triplet-state quenching discussed in detail by Wilkinson [Eq. (14) - (16)], ${ }^{[44]}$ the rate constant of the quenching by oxygen $\left(k_{\mathrm{q}}=k_{\mathrm{T} \Delta}+k_{\mathrm{T} \Sigma}\right)$ can be obtained from the lifetimes of the triplet in $\mathrm{N}_{2}$ and airsaturated solutions from Equation (17), taking $\left[\mathrm{O}_{2}\right]=1.81 \times$ $10^{-3} \mathrm{M}$ in toluene at room temperature. ${ }^{[42]}$

$$
\begin{aligned}
& { }^{3} \mathrm{M} \longrightarrow{ }^{1} \mathrm{M} \\
& { }^{3} \mathrm{M}+{ }^{3} \mathrm{O}_{2} \stackrel{k_{\text {TA }}}{\longrightarrow}{ }^{1} \mathrm{M}+{ }^{1} \mathrm{O}_{2} \\
& { }^{3} \mathrm{M}+{ }^{3} \mathrm{O}_{2} \stackrel{{ }^{k_{\mathrm{T}}}}{\longrightarrow} \text { quenching } \\
& k_{\mathrm{q}}\left[\mathrm{O}_{2}\right]=\frac{1}{\tau_{2}\left(\mathrm{~N}_{2}\right)}-\frac{1}{\tau_{2}(\text { air })}
\end{aligned}
$$

When $\tau_{2}\left(\mathrm{~N}_{2}\right)>10 \mu$ s we simply take $k_{\mathrm{q}}\left[\mathrm{O}_{2}\right]=1 / \tau_{2}$ (air). Some properties of the triplet states of the porphyrins and chlorin are presented in Table 2. The present results are in good agreement with the literature data for TPP, $\mathrm{Zn}-\mathrm{TPP}$ and $\mathrm{Cu}$-TPP. The fractions of $\mathrm{O}_{2}\left({ }^{1} \Delta_{\mathrm{g}}\right)$ formed from the triplet state of the sensitisers are all close to unity $\left(f_{\Delta}^{\mathrm{T}} \approx 1\right)$, except for $\mathrm{Cu}-\mathrm{TPP}$, which will be discussed below. This indicates that $k_{\mathrm{T} \Delta} \geq 10 k_{\mathrm{T} \Sigma}$.

Following the pioneering work of Porter ${ }^{[45]}$ it is believed that when $k_{\mathrm{q}} \approx 1 / 9 k_{\text {diff }}$ the quenching of triplet states by molecular oxygen follows an energy-transfer mechanism. In toluene at room temperature $1 /{ }_{9} k_{\text {diff }}=3.4 \times 10^{9} \mathrm{M}^{-1} \mathrm{~s}^{-1} \cdot{ }^{[42]}$ The rates measured in our study are slightly below $1 /{ }_{9} k_{\text {diff }}$ and, with the exception of $\mathrm{Cu}-\mathrm{TPP}$, tend to decrease as $E_{\mathrm{T}}$ increases (Figure 5). A similar trend for energy gaps $\left(\Delta E=E_{\mathrm{T}}-E_{\Delta}\right)$ between 40 and $200 \mathrm{~kJ} \mathrm{~mol}^{-1}$ was also apparent in the work of

\begin{tabular}{|c|c|c|c|c|c|c|c|}
\hline & $\Phi_{\mathrm{T}}$ & $\Phi_{\Delta}[\mathrm{b}]$ & $\Phi_{\Delta}[\mathrm{c}]$ & $f_{\Delta}^{\mathrm{T}}$ & $\begin{array}{l}\tau_{\mathrm{T}}\left(\mathrm{N}_{2}\right) \\
{[\mathrm{ns}]}\end{array}$ & $\begin{array}{l}\tau_{\mathrm{T}}\left(\mathrm{O}_{2}\right) \\
{[\mathrm{ns}]}\end{array}$ & $\begin{array}{l}k_{\mathrm{q}} \times 10^{-9} \\
{\left[\mathrm{M}^{-1} \mathrm{~s}^{-1}\right]}\end{array}$ \\
\hline TPP & $0.73 \pm 0.10$ & $0.67 \pm 0.14$ & $0.55-0.72$ & $0.92 \pm 0.22$ & $>10000$ & $196 \pm 6$ & $2.82 \pm 0.02$ \\
\hline TNC & $0.55 \pm 0.10$ & $0.54 \pm 0.06$ & & $0.98 \pm 0.17$ & $1390 \pm 99$ & $545 \pm 130$ & $0.62 \pm 0.12$ \\
\hline $\mathrm{Zn-TPP}$ & $0.86 \pm 0.17$ & $0.68 \pm 0.19$ & $0.68-0.92$ & $0.79 \pm 0.26$ & $>10000$ & $309 \pm 31$ & $1.79 \pm 0.07$ \\
\hline $\mathrm{Zn}-\mathrm{TNP}$ & $0.90 \pm 0.10$ & $0.76 \pm 0.11$ & & $0.84 \pm 0.15$ & $>10000$ & $424 \pm 34$ & $1.30 \pm 0.08$ \\
\hline Zn-TDFPP & $0.99 \pm 0.04$ & $0.99 \pm 0.05$ & & $1.00 \pm 0.06$ & $5921 \pm 597$ & $604 \pm 5$ & $0.82 \pm 0.06$ \\
\hline Zn-TDCPP & $1.02 \pm 0.01$ & $0.90 \pm 0.07$ & & $0.88 \pm 0.07$ & $4185 \pm 890$ & $738 \pm 59$ & $0.62 \pm 0.02$ \\
\hline $\mathrm{Cu}-\mathrm{TPP}$ & $0.88 \pm 0.02$ & $0.03 \pm 0.01$ & $<0.01^{[\mathrm{d}]}$ & $0.04 \pm 0.01$ & $17.8 \pm 1.5$ & $15.9 \pm 0.7$ & $11.6 \pm 0.09$ \\
\hline
\end{tabular}
Porter and was investigated in detail by Schmidt and coworkers. ${ }^{[46]}$ The energy-gap dependence of long-distance

Table 2. Quantum yields and triplet lifetimes in toluene measured by time-resolved photoacoustic calorimetry. ${ }^{[a]}$

[a] The uncertainties are calculated for a $95 \%$ confidence level. [b] Values of $\Phi_{\Delta}(\mathrm{TNP})=0.66, \Phi_{\Delta}(\mathrm{TNC})=0.68$ and $\Phi_{\Delta}(\mathrm{Zn}-\mathrm{TNP})=0.77$ relative to $\Phi_{\Delta}(\mathrm{TPP})=0.66$ were measured, with the same samples, at the Free Radical Research Facility of the Paterson Institute for Cancer Research (Manchester, U.K.) by means of the method described by Bonnett et al in ref. [10]. [c] Range of values in benzene or toluene solutions reported in ref. [14]. [d] Limit in $\mathrm{CCl}_{4}$ reported in ref. [14]. 


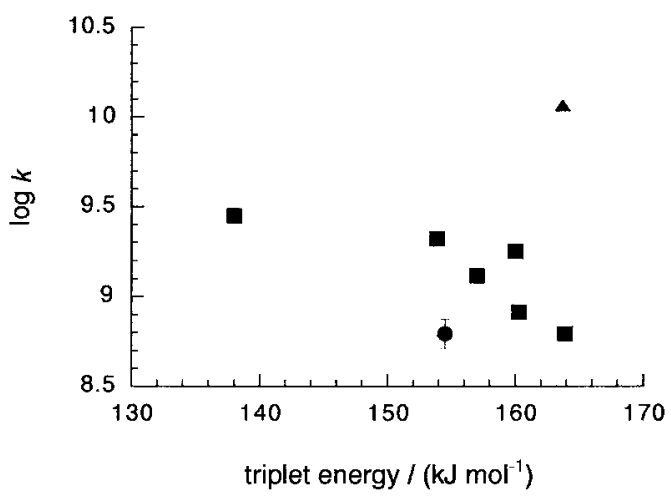

Figure 5. Energy-gap dependence of triplet-quenching rate constants by molecular oxygen $\left(E_{\Delta}=94 \mathrm{~kJ} \mathrm{~mol}^{-1}\right)$. The circle represents the quenching of the triplet state of TNC, and suggests that chlorins and porphyrins have different Franck - Condon factors. The triangle represents the quenching of $\mathrm{Cu}-\mathrm{TPP}$, which follows a different mechanism.

triplet energy-transfer rates was interpreted as the simultaneous transfer of two electrons, ${ }^{[47,48]}$ with the electronexchange mechanism originally proposed by Dexter. ${ }^{[49]} \mathrm{A}$ quantitative interpretation of long-distance triplet energytransfer reaction rates was offered by the intersecting-state model (ISM). ${ }^{[50]}$ The rates of energy transfers taking place between reactants in close contact, such as those measured in this study, will depend on the details of the orbital interactions that allow electron exchange. ${ }^{[51]}$ Such electron exchanges may have some inner-sphere character, and the energy-transfer rates calculated with ISM assuming an outer-sphere mechanism tend to underestimate the experimental rates, especially for near-resonance transfers.

The luminescence of $\mathrm{Cu}-\mathrm{TPP}$ originates from the triplet manifold of the porphyrin. ${ }^{[52,53]}$ Adding the $1.5 \mathrm{~kJ} \mathrm{~mol}^{-1}$ correction to the energy obtained from the maximum of the emission band we obtain $E_{\mathrm{T}}=163.7 \mathrm{~kJ} \mathrm{~mol}^{-1}$. Equation (7), with $\phi_{1}=0.4967 \pm 0.0133$ and $\Phi_{\mathrm{F}}=0$, gives $\Phi_{\mathrm{T}}=0.88 \pm 0.02$. This result may be unexpected in view of the fast intersystemcrossing rates. However, the transient absorption of $\mathrm{Cu}-\mathrm{TPP}$ in toluene relaxes by $10-15 \%$ between $40 \mathrm{ps}$ and $2.4 \mathrm{~ns},{ }^{[54]}$ and $\Phi_{\mathrm{T}}$ should be in the range of $0.85-0.90$. Our results suggest that most of the initially excited singdoublet $\left({ }^{2} \mathrm{Q}\right)$ relaxes very rapidly to the emissive tripdoublet $\left({ }^{2} \mathrm{~T}\right)$ and tripquartet $\left({ }^{4} \mathrm{~T}\right)$ states, while a smaller fraction returns to the ground state $\left({ }^{2} \mathrm{~S}_{0}\right)$ probably via a charge-transfer (CT) state.

The relevance of a low-energy $\mathrm{CT}$ state in $\mathrm{Cu}-\mathrm{TPP}$ is supported by the large triplet-quenching rate in the presence of molecular oxygen. Wilkinson proposed the involvement of CT complexes in oxygen quenching to account for rate constants larger than $1 / 9 k_{\text {diff }} \cdot{ }^{[55,56]}$ When triplet quenching via CT complexes is diffusion-limited, the quenching rate constant expected is ${ }^{4} /{ }_{9} k_{\text {diff }}\left(=1.4 \times 10^{10} \mathrm{M}^{-1} \mathrm{~s}^{-1}\right.$ in toluene $)$, and the limiting value of $f_{\Delta}^{\mathrm{T}}$ is 0.25 . We calculated $f_{\Delta}^{\mathrm{T}}=0.038$ using Equation (12), which presumes a phosphorescence quantum yield $\Phi_{\mathrm{P}} \approx 0$ in room-temperature air-saturated toluene solutions of $\mathrm{Cu}$-TPP. It seems that in the encounter complex between excited $\mathrm{Cu}-\mathrm{TPP}$ and molecular oxygen the energy of the CT state is lowered and becomes a very effective dissipative channel.

\section{Conclusions}

This work describes a reliable methodology for the measurement of singlet-oxygen quantum yields in solution by means of time-resolved photoacoustic calorimetry and luminescence techniques. We show that the presence of two chlorine atoms in the ortho positions of the phenyl ring in TPP is sufficient to increase the intersystem crossing rate to yield the triplet state quantitatively, and yet this state lives long enough to sensitise singlet oxygen with unit quantum yield. The presence of lowenergy charge-transfer states may accelerate the sensitisation of singlet oxygen, but it also opens other radiationless channels that waste a significant part of the energy absorbed.

The molecules synthesised in this study have the photochemical properties required for a good PDT sensitiser. However, none gather all the necessary biological and photochemical properties simultaneously. The synthesis of chlorins with hydroxyl and sulfonamide substituents, in addition to chlorine substituents, is in progress in our laboratory and is expected to more closely approach the desired properties of a PDT sensitiser.

\section{Experimental Section}

Instrumentation: ${ }^{1} \mathrm{H}$ NMR spectra were recorded on $300 \mathrm{Mhz}$ Bruker AMX spectrometer. Mass spectra were obtained on a VG autospec and elemental analysis on EA1108-CHNS-0 Fisons Instruments. Absorption and luminescence spectra were recorded with Shimadzu UV-2100 and SPEX Fluorog 111 spectrophotometers, respectively.

Luminescence measurements: Fluorescence quantum yields $\left(\Phi_{\mathrm{F}}\right)$ were measured by the method described by Parker and Rees. ${ }^{[57]}$ Carefully diluted solutions of each porphyrin in toluene with absorbance 0.02 at the excitation wavelength $(417 \mathrm{~nm})$ were deaerated with $\mathrm{N}_{2}$ saturated in toluene and kept in the dark before the measurements. Using 1,4dihydroxyanthraquinone as reference, ${ }^{[58]}$ we obtained $\Phi_{\mathrm{F}}=0.10$ for TPP, in agreement with literature data. ${ }^{[30]}$ The other $\Phi_{\mathrm{F}}$ values were obtained with $\Phi_{\mathrm{F}}=0.10$ for TPP. The phosphorescence studies were carried out in toluene at liquid nitrogen temperature, with excitation at the Soret band. Second-order harmonics were eliminated with appropriate filters. Fluorescence and phosphorescence excitation spectra were obtained for all the porphyrins and agreed well with the corresponding absorption spectra.

Photoacoustic measurements: The PAC apparatus follows the front-face irradiation design described by Arnaut et al. (Figure 6). ${ }^{[18]}$ The solutions were pumped through a $0.11 \mathrm{~mm}$ thick cell at a $1 \mathrm{~mL} \mathrm{~min}^{-1}$ flow rate with an SSI chromatography pump, and irradiated with an unfocused PTI dye laser (model PL2300), pumped by a $\mathrm{N}_{2}$ laser working at a frequency of 2 Hz. TPP, $\mathrm{Zn}-\mathrm{TPP}, \mathrm{Zn}-\mathrm{TNP}, \mathrm{Zn}-\mathrm{TDFPP}, \mathrm{Zn}$-TDCPP and $\mathrm{Cu}-\mathrm{TPP}$ were irradiated at $421 \mathrm{~nm}$, whereas TNP and TNC were irradiated at $517 \mathrm{~nm}$. More than $99 \%$ of the light impinging on the front-face dielectric mirror is reflected back into the solution; the rest is transmitted, minimising the background signal. We measured the $\mathrm{N}_{2}$ laser energy using Aberchrome (Aberchromics Ltd.) as actinometer and obtained $1.0 \mathrm{~mJ} /$ pulse in the PAC cell; the energy of the dye lasers is about $10 \%$ that of the $\mathrm{N}_{2}$ laser. A small fraction of the laser beam was deflected to a photodiode in order to trigger the digital storage oscilloscope (Tektronix DSA 601, $1 \mathrm{Gss}^{-1}$, two channels). The acoustic waves generated by nonradiative processes following light absorption in the cell were detected with a $2.25 \mathrm{MHz}$ Panametrics transducer (model A106S), pre-amplified with a Panametrics ultrasonic preamplifier (model 5676), captured by the transient recorder and transferred to a PC for data analysis. The decay of the triplet state of $\mathrm{Cu}-\mathrm{TPP}$ was measured with a Panametrics $15 \mathrm{MHz}$ transducer (model A113S) given the short lifetime expected: $29 \mathrm{~ns}$ in toluene. ${ }^{[59]}$ Prior to each PAC experiment, we matched to better than $1 \%$ the absorbances of sample and reference at the irradiation wavelength. We collected and averaged 




Figure 6. Front-face cell used in PAC. The dielectric mirrors are specific for each dye laser and reflect more than $99.5 \%$ of the incident light. The remaining light is transmitted. The laser beam is defocused to match the diameter of the transducer.

100 acoustic waves of the sample, reference and pure solvent in the same conditions. Four sets of averaged sample, reference and solvent waves were used for data analysis at a given laser intensity, and four laser intensities were employed in each experiment. These laser intensities were obtained by interposing filters with transmissions in the 30 to $100 \%$ range. The sample solutions used in the oxygen photosensitisation measurements were saturated with air; in the other measurements they were deaerated by purging with solvent-saturated $\mathrm{N}_{2}$. The pure solvent signal was scaled by the fraction of light absorbed by the sample in the PAC cell (typically $5 \%$ ) and subtracted from the sample and reference signals. All the measurements were made in toluene solutions with Mn-TPP as photoacoustic reference.

Materials: All solvents and reagents (Aldrich) were purified by standard methods before use. The toluene employed in PAC studies was first washed with sulfuric and nitric acids and then with distilled water until neutralisation. Most of the water was removed by adding anhydrous $\mathrm{CaCl}_{2}$; the toluene was then filtered and distilled over $\mathrm{P}_{2} \mathrm{O}_{5}$. We added sodium and benzophenone to the distilled toluene, and refluxed the mixture until it turned blue, indicating that all traces of water were eliminated. The toluene was then re-distilled.

General porphyrin syntheses: Porphyrins were synthesised by a method developed by Rocha Gonsalves et al. ${ }^{[23]}$ The general procedure is as follows. In a typical reaction, arylaldehyde $\left(0.4 \times 10^{-3} \mathrm{~mol}\right)$ were dissolved in a mixture of acetic acid $(140 \mathrm{~mL}, 2.45 \mathrm{~mol})$ and nitrobenzene $(70 \mathrm{~mL}$, $0.68 \mathrm{~mol})$, and the temperature was raised to $120^{\circ} \mathrm{C}$. Pyrrole $(2.8 \mathrm{~mL}, 0.4 \times$ $10^{-3} \mathrm{~mol}$ ) was then added. The reaction was followed by UV/Vis spectroscopy, and the temperature was maintained until the Soret-band intensity reaches a maximum. The solution was cooled to room temperature to give porphyrin crystals, which were filtered off, washed with methanol and dried. Simple recrystallisation from dichloromethane/methanol (10:1) gave the compounds with yields and characterisation presented below.

5,10,15,20-Tetraphenylporphyrin: Yield: $20 \%$; ${ }^{1} \mathrm{H} \quad \mathrm{NMR} \quad(300 \mathrm{MHz}$, $\left.\mathrm{CDCl}_{3}\right): \delta=8.89(\mathrm{~s}, 8 \mathrm{H}), 8.19-8.31(\mathrm{~m}, 12 \mathrm{H}), 7.75(\mathrm{~m}, 8 \mathrm{H}),-2.77$ (brs, $2 \mathrm{H}$ ); MS (FAB): $m / z=615$ (molecular ion); $\mathrm{C}_{44} \mathrm{H}_{30} \mathrm{~N}_{4}$ : calcd C 85.97, $\mathrm{H}$ 4.92, N 9.12; found C 85.71, H 4.78, N 9.02.

5,10,15,20-Tetrakis(2,6-difluorophenyl)porphyrin: Yield: $11 \% ;{ }^{1} \mathrm{H}$ NMR $\left(300 \mathrm{MHz}, \mathrm{CDCl}_{3}\right): \delta=8.88(\mathrm{~s}, 8 \mathrm{H}), 7.73-7.89(\mathrm{~m}, 4 \mathrm{H}), 7.32-7.44(\mathrm{~m}, 8 \mathrm{H})$, -2.76 (brs, $2 \mathrm{H}$ ); MS (FAB): $m / z=759$ (molecular ion); $\mathrm{C}_{44} \mathrm{H}_{22} \mathrm{~N}_{4} \mathrm{~F}_{8}$ : calcd C 69.66, H 2.92, N 7.38; found C 69.72, H 2.91, N 6.91.

5,10,15,20-Tetrakis(2,6-dichlorophenyl)porphyrin: Yield: $5 \%$; ${ }^{1} \mathrm{H}$ NMR $\left(300 \mathrm{MHz}, \mathrm{CDCl}_{3}\right): \delta=8.62(\mathrm{~s}, 8 \mathrm{H}), 7.65-7.85(\mathrm{~m}, 12 \mathrm{H}),-2.59(\mathrm{brs}, 2 \mathrm{H})$; MS (FAB): $m / z=887-905$ ( $\mathrm{Cl}$ isotopes for molecular ion); $\mathrm{C}_{44} \mathrm{H}_{22} \mathrm{~N}_{4} \mathrm{Cl}_{8}$ : calcd C 59.36, H 2.49, N 6.29; found C 59.30, H 2.47, N 6.25.
5,10,15,20-Tetranaphthylporphyrin: Yield: $23 \%$; ${ }^{1} \mathrm{H}$ NMR $\left(300 \mathrm{MHz}, \mathrm{CDCl}_{3}\right): \delta=8.47(\mathrm{~s}, 8 \mathrm{H})$, $8.21-8.30(\mathrm{~m}, 8 \mathrm{H}), 8.09-8.12(\mathrm{~d}, 4 \mathrm{H}), 7.79-7.85$ $(\mathrm{m}, 4 \mathrm{H}), 7.44-7.49(\mathrm{~m}, 4 \mathrm{H}), 7.08-7.21(\mathrm{~m}, 8 \mathrm{H})$, -2.25 (brs, $2 \mathrm{H}$ ); MS (FAB): $m / z=815$ (molecular ion); $\mathrm{C}_{60} \mathrm{H}_{38} \mathrm{~N}_{4}$ : calcd C 88.42, $\mathrm{H} 4.70, \mathrm{~N} 6.88$; found C 88.44, H 4.71, N 6.86.

$\mathbf{5 , 1 0 , 1 5 , 2 0 - T e t r a n a p h t h y l c h l o r i n ~ s y n t h e s i s : ~ W e ~ u s e d ~}$ the method of Whitlock ${ }^{[28]}$ to synthesise this chlorin. 5,10,15,20-Tetranaphthylporphyrin $(0.05 \mathrm{~g}$, $0.06 \mathrm{mmol})$ and sodium carbonate $(3 \mathrm{~g}, 0.02 \mathrm{~mol})$ were dissolved in freshly distilled $\gamma$-picoline $(50 \mathrm{~mL})$, and the mixture was heated to $140^{\circ} \mathrm{C}$. A solution of $p$-toluenesulfonylhydrazine in $\gamma$-picoline $(10 \mathrm{~mL}, 0.4 \mathrm{M})$ was added to the reaction mixture. The reaction, monitored by UV/Vis spectroscopy, was complete in 6 hours. After workup, the product was chromatographed with dichloromethane/hexane (1:3) in silica preparative thinlayer, and the second fraction was separated. The silica was washed with dichloromethane, and the chlorin was recrystallised from dichloromethane/ hexane (10:1). Yield: $51 \%$; ${ }^{1} \mathrm{H}$ NMR $(300 \mathrm{MHz}$, $\left.\mathrm{CDCl}_{3}\right): \delta=8.29-8.31(\mathrm{~m}, 6 \mathrm{H}), 8.14-8.22(\mathrm{~m}, 8 \mathrm{H})$, $8.08-8.09(\mathrm{~m}, 8 \mathrm{H}), 7.94-8.03(\mathrm{~m}, 8 \mathrm{H}), 7.78-7.83$ $(\mathrm{m}, 4 \mathrm{H}), 7.40-7.54(\mathrm{~m}, 4 \mathrm{H}), 3.80(\mathrm{~s}, 4 \mathrm{H}),-0.99(\mathrm{~s}$, $2 \mathrm{H}$ ); MS (FAB): $m / z=817$ (molecular ion); $\mathrm{C}_{60} \mathrm{H}_{40} \mathrm{~N}_{4}$ : calcd $\mathrm{C} 88.20, \mathrm{H}$ 4.94, N 6.86; found C 88.18, H 4.91, N 6.84 .

General metalloporphyrin syntheses: Porphyrin metal complexes were synthesised by the method of Adler. ${ }^{[27]}$ Porphyrin $(0.07 \mathrm{mmol})$ was dissolved in dimethylformamide $(50 \mathrm{~mL})$ and heated to $150^{\circ} \mathrm{C}$. The desired metal acetate salt $(0.4 \mathrm{~mol})$ was added. The reaction was monitored by UV/ Vis spectroscopy. After workup, the metal complex was purified by silicagel column chromatography with the appropriate dichloromethane/hexane ratio. Recrystallisation from dichloromethane/hexane gave the isolated products with yields described below.

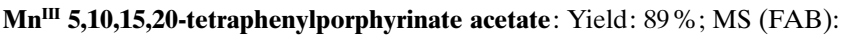
$m / z=667$ (molecular ion -acetate); UV/Vis (toluene): $\lambda(\varepsilon)=477.40$ $\left(1.1 \times 10^{5}\right), 534.0\left(5.4 \times 10^{3}\right), 585.4\left(8.4 \times 10^{3}\right), 621.0 \mathrm{~nm}\left(9.9 \times 10^{3}\right)$. Although this is a $\mathrm{Mn}^{\mathrm{III}}$ complex involving acetate ion as ligand, we abbreviate it as Mn-TPP. $\mathrm{C}_{46} \mathrm{H}_{31} \mathrm{~N}_{4} \mathrm{O}_{2} \mathrm{Mn}$ : calcd C 77.74, $\mathrm{H}$ 4.40, N 7.88; found C 77.64, $\mathrm{H} 4.51, \mathrm{~N} 7.84$.


$\left.\mathrm{CDCl}_{3}\right): \delta=8.85(\mathrm{~s}, 8 \mathrm{H}), 8.20(\mathrm{~m}, 8 \mathrm{H}), 7.75(\mathrm{~m}, 12 \mathrm{H}) ; \mathrm{MS}(\mathrm{FAB}): m / z=$ 676 (molecular ion). $\mathrm{C}_{44} \mathrm{H}_{28} \mathrm{~N}_{4} \mathrm{Zn}$ : calcd $\mathrm{C} 77.93, \mathrm{H} \mathrm{4.16,} \mathrm{N} \mathrm{8.26;} \mathrm{found} \mathrm{C}$ 76.94, H 4.12, N 7.80.

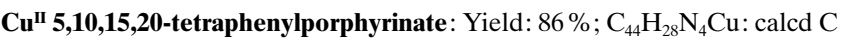
78.15, H 4.17, N 8.28; found C 78.12, H 4.48, N 8.28.

$\mathbf{Z n}^{\text {II }}$ 5,10,15,20-tetranaphthylporphyrinate: Yield: $93 \%$; ${ }^{1} \mathrm{H} \quad$ NMR $\left(300 \mathrm{MHz}, \mathrm{CDCl}_{3}\right): \delta=8.56(\mathrm{~s}, 8 \mathrm{H}), 8.20-8.30(\mathrm{~m}, 8 \mathrm{H}), 8.09-8.12(\mathrm{~d}$, $4 \mathrm{H}), 7.80-7.85(\mathrm{~m}, 4 \mathrm{H}), 7.44-7.49(\mathrm{~m}, 4 \mathrm{H}), 7.07-7.23(\mathrm{~m}, 8 \mathrm{H})$; $\mathrm{C}_{60} \mathrm{H}_{36} \mathrm{~N}_{4} \mathrm{Zn}$ : calcd C 82.05, H 4.13, N 6.38; found C 81.97, H 4.71, N 6.41.

$\mathbf{Z n}^{\text {II }}$ 5,10,15,20-tetrakis(2,6-difluorophenyl)porphyrinate: Yield: $87 \%$; ${ }^{1} \mathrm{H}$ $\operatorname{NMR}\left(300 \mathrm{MHz}, \mathrm{CDCl}_{3}\right): \delta=8.81(\mathrm{~s}, 8 \mathrm{H}), 7.60-7.74(\mathrm{~m}, 4 \mathrm{H}), 7.20-7.36$ $(\mathrm{m}, 8 \mathrm{H}) ; \mathrm{MS}$ (FAB): $m / z=822$ (molecular ion); $\mathrm{C}_{44} \mathrm{H}_{20} \mathrm{~N}_{4} \mathrm{~F}_{8} \mathrm{Zn}$ : calcd $\mathrm{C}$ 64.29, H 2.45, N 6.82; found C 63.71, H 2.96, N 6.35.

ZnII 5,10,15,20-tetrakis(2,6-chlorophenyl)porphyrinate: Yield: $67 \%$; ${ }^{1} \mathrm{H}$ $\operatorname{NMR}\left(300 \mathrm{MHz}, \mathrm{CDCl}_{3}\right): \delta=8.70(\mathrm{~s}, 8 \mathrm{H}), 7.60-7.80(\mathrm{~m}, 12 \mathrm{H})$; MS (FAB): $m / z=954$ (peak centred); $\mathrm{C}_{44} \mathrm{H}_{20} \mathrm{~N}_{4} \mathrm{Cl}_{8} \mathrm{Zn}$ : calcd C 55.42, H 2.11, N 5.87; found C 55.64, H 2.42, N 5.64.

Acknowledgments: The authors are grateful to Dr. Hugh Burrows for the measurements at the Paterson Institute for Cancer Research and to Dr. C. Claver (University of Rovira Virgilli, Tarragona, Spain) for mass spectral measurements. We thank the Fundação para a Ciência e a Tecnologia (PRAXIS XXI contract no. 2/2.1/QUI/390/94) for financial support. M.P. received a scholarship from PRAXIS XXI/BD/11398/97.

Received: March 12, 1998 [F1049] 
[1] J. Deisenhofer, O. Epp, K. Miki, R. Huber, H. Michel, J. Mol. Biol. 1984, 180, 385.

[2] T. Takano, R. E. Dickerson, J. Mol. Biol. 1981, 153, 79.

[3] T. Takano, R. E. Dickerson, J. Mol. Biol. 1981, 153, 95.

[4] B. Shaanan, J. Mol. Biol. 1983, 171, 31.

[5] G. Fermi, M. F. Perutz, B. Shaanan, J. Mol. Biol. 1984, 175, 159.

[6] B. Franck, A. Nonn, Angew. Chem. 1995, 107, 1941; Angew. Chem. Int. Ed. Engl. 1995, 34, 1795.

[7] R. V. Bensasson, E. J. Land, T. G. Truscott, Excited States and Free Radicals in Biology and Medicine, Oxford University Press, Oxford, 1993, p. 341.

[8] K. Berg, in The Fundamental Bases of Phototherapy (Eds.: H. Hönigsmann, G. Jori, A. R. Young), OEMF spa, Milano, 1996, p. $181-207$.

[9] T. J. Dougherty, Photochem. Photobiol. 1993, 58, 895.

[10] R. Bonnett, D. J. McGarvey, A. Harriman, E. J. Land, T. G. Truscott, V. J. Winfield, Photochem. Photobiol. 1988, 48, 271.

[11] J. Olmsted III, J. Am. Chem. Soc. 1980, 102, 66.

[12] K. Kikuchi, Y. Kurabayashi, H. Korubun, Y. Kaizu, H. Kobayashi, J. Photochem. Photobiol. A: Chem. 1988, 45, 261.

[13] T. A. Moore, D. Benin, R. Tom, J. Am. Chem. Soc. 1982, 104, 7356.

[14] F. Wilkinson, W. P. Helman, A. B. Ross, J. Phys. Chem. Ref. Data 1993, $22,113$.

[15] S. E. Braslavsky, Photobiochem. Photobiophys. 1987, Suppl., 83.

[16] R. W. Redmond, S. E. Braslavsky, Chem. Phys. Lett. 1988, 148, 523.

[17] S. E. Braslavsky, G. E. Heibel, Chem. Rev. 1992, 92, 1381.

[18] L. G. Arnaut, R. A. Caldwell, J. E. Elbert, L. A. Melton, Rev. Sci. Instrum. 1992, 63, 5381.

[19] M. M. Pereira, Ph.D. Thesis, Coimbra, Portugal, 1992

[20] D. A. Bellnier, W. R. Greco, J. C. Parsons, A. R. Oseroff, A. Kuebler, T. J. Dougherty, Photochem. Photobiol. 1997, 66, 237.

[21] P. Rothemund, J. Am. Chem. Soc. 1935, 57, 2010.

[22] A. D. Adler, F. R. Longo, J. D. Finarelli, J. Goldmacher, J. Assour, L. Karsakoff, J. Org. Chem. 1967, 32, 476.

[23] A. M. d'A. Rocha Gonsalves, J. M. T. B. Varejão, M. M. Pereira, J. Heterocycl. Chem. 1991, 28, 635.

[24] Z. H. Skraup, Ber. 1880, 13, 2086.

[25] K. R. Reddy, K. Mogilaiah, B. Sreenivasulu, Ind. J. Chem. B 1987, 26, 1194.

[26] R. A. W. Johnstone, M. L. P. G. Nunes, M. M. Pereira, A. M. d'A. Rocha Gonsalves, A. C. Serra, Heterocycles 1996, 43, 1423.

[27] A. D. Adler, F. R. Longo, F. Kampas, Inorg. Chem. 1979, 32, 2443.
[28] H. W. Whitlock, Jr., R. Hanauer, M. Y. Oester, B. K. Bower, J. Am. Chem. Soc. 1969, 91, 7485 .

[29] P. G. Seybold, M. Gouterman, J. Mol. Spectrosc. 1969, 31, 1.

[30] D. J. Quimby, F. R. Longo, J. Am. Chem. Soc. 1975, 97, 5111

[31] A. Harriman, J. Chem. Soc. Faraday Trans. I 1981, 77, 369.

[32] S. Nonell, P. F. Aramendía, K. Heihoff, R. M. Negri, S. E. Braslavsky, J. Phys. Chem. 1990, 94, 5879.

[33] K. Heihoff, R. W. Redmond, S. E. Braslavsky, M. Rougée, C. Salet, A. Favre, R. V. Bensasson, Photochem. Photobiol. 1990, 51, 635.

[34] T. Gensch, S. E. Braslavsky, J. Phys. Chem. B 1997, 101, 101.

[35] R. S. Becker, J. B. Allison, J. Phys. Chem. 1963, 67, 2662.

[36] A. Harriman, J. Chem. Soc. Faraday I 1980, 76, 1978.

[37] S.-Y. Hou, W. M. Hetherington III, G. M. Korenowski, K. B. Eisenthal, Chem. Phys. Lett. 1979, 68, 282.

[38] M. R. Wasielewski, L. D. Kispert, Chem. Phys. Lett. 1986, 128, 238.

[39] T. Gillbro, R. J. Cogdell, Chem. Phys. Lett. 1989, 158, 312.

[40] L. A. Melton, T. Ni, Q. Lu, Rev. Sci. Instrum. 1989, 60, 3217.

[41] R. Bonnett, A. Harriman, A. N. Kozyrev, J. Chem. Soc. Faraday Trans. 1992, 88, 763 .

[42] A. P. Darmanyan, C. S. Foote, J. Phys. Chem. 1993, 97, 5032.

[43] J. Feitelson, D. Mauzerall, J. Phys. Chem. 1996, 100, 7698.

[44] F. Wilkinson, Pure Appl. Chem. 1997, 69, 851.

[45] O. L. J. Gijzemann, F. Kaufman, G. Porter, J. Chem. Soc., Faraday Trans. II 1973, 69, 708.

[46] M. Bodesheim, M. Schütz, R. Schmidt, Chem. Phys. Lett. 1994, 221, 7.

[47] G. L. Closs, M. D. Johnson, J. R. Miller, P. Piotrowiak, J. Am. Chem. Soc. 1989, 111, 3751.

[48] M. E. Sigman, G. L. Closs, J. Phys. Chem. 1991, 95, 5012.

[49] D. L. Dexter, J. Chem. Phys. 1953, 21, 836.

[50] S. J. Formosinho, L. G. Arnaut, R. Fausto, Prog. React. Kinet. 1998, 23, 1.

[51] N. J. Turro, Pure Appl. Chem. 1977, 49, 405.

[52] M. Asano-Someda, Y. Kaizu, J. Photochem. Photobiol. A: Chem. 1995, 87, 23.

[53] K. L. Cunningham, K. M. McNett, R. A. Pierce, K. A. Davies, H. H. Harris, D. M. Falck, D. R. McMillin, Inorg. Chem. 1997, 36, 608.

[54] D. Kim, D. Holten, M. Gouterman, J. Am. Chem. Soc. 1984, 106, 2793.

[55] A. Garner, F. Wilkinson, Chem. Phys. Lett. 1977, 45, 432.

[56] F. Wilkinson, A. A. Abdel-Shafi, J. Phys. Chem. A 1997, 101, 5509.

[57] C. A. Parker, T. W. Rees, Analyst 1960, 85, 587.

[58] D. K. Palit, H. Pal, T. Mukherjee, J. P. Mittal, J. Chem. Soc. Faraday Trans. 1990, 86, 3861.

[59] M. Asano, Y. Kaizu, H. Kobayashi, J. Chem. Phys. 1988, 89, 6567. 